\title{
PROBLEMS OF THE INDUSTRY EARNINGS STANDARD $\dagger$
}

\author{
Franz B. Wolf $\ddagger$ and Forrest E. Keller*
}

The essential idea embodied in an Industry Earnings Standard ${ }^{1}$ is a normal level of industry earnings as a limit to the requirement of cost absorption. It neither guarantees the industry a normal level of profit nor denies it some higher level.

Operationally it provides the practical answer to "how low is too low?" for an industry's ceiling prices. It says that if ceiling prices are so low that the industry cannot realize normal profits, over-all and on the average, the ceilings are too low.

Once they understand it, very few people would have any disposition (at least openly) to quarrel with this essential idea of any Industry Earnings Standard. That is to say, few would feel that any industry's price ceilings were in general so low as to impose hardship even though that industry were averaging what could defensibly be termed normal profits. At the same time, this essential idea of an Industry Earnings Standard is one that is both conceptually and practically consistent with effective stabilization.

The operation and effect of any Industry Earnings Standard is determined by (I) the terms of its basic formulation, (2) the rules and procedures devised for, and . those actually used in its case-by-case application, and (3) the measures calculated to maximize understanding, acceptance, and cooperation within and between the price-control organization and the business community.

No one of these three elements can realistically be regarded as a prime or independent variable, so to speak. To work out earnings standard problems arising in any one of the three contexts without regard for the other two tends to be futile, for a "solution" embodied in the terms of the basic formulation solves nothing at all, unless it can be, and actually is translated into procedures for application and is sufficiently understood to make the results of its application acceptable to all concerned, inside and outside the price control agency. Equally, measures to obtain acceptance tend to be futile if such acceptance is based on a view of the standard which is at odds with the terms of its formulation or which cannot be put into practical execution. Nor is there any point in solving problems arising in application, unless the solution is in harmony with the terms of the basic formulation and at the same time produces acceptable results.

Policy formulation, administrative application, and attainment of acceptance, of course, are interdependent in all phases of democratic government, just as design,

†The opinions expressed herein are the authors' and do not necessarily reflect the position of any past or present Government agency.

¥ Former Deputy Director, Office of Economic Policy, Office of Price Stabilization.

- Former Assistant Director, Office of Economic Policy, Office of Price Stabilization.

${ }^{2}$ For a brief description and account of the Industry Earnings Standard of OPS, see Nelson, OPS Price Control Standards, supra, pp. 573-575. 
production, and selling in private business. Special importance, however, attaches to this fact in those situations where each of the three steps involves problems that defy neat solution. The Industry Earnings Standard is peculiarly one of these cases. Recognition of, and emphasis on the interdependence of the three stages of realization appears to be the most important lesson that can be drawn from the OPS experience with that standard.

Little purpose would be served here by relating, step by step, the experiences from which this conclusion arises. Instead, an effort will be made to analyze some of the major problems raised by the Industry Earnings Standard, while bearing all three stages in mind.

\section{I}

\section{The Concept of Normalcy}

Price control is regarded as an abnormal condition in the market economy of a democratic society. It is accepted only as an emergency measure, an element in a system of governmental actions designed to absorb and distribute the special burdens arising from that emergency. Legal authority for price control, therefore, implies no consent to letting a government agency establish prices which are to be accepted as normal. On the contrary, the requirement is that the agency's ceiling prices must not too far depart from normalcy, i.e., from a free-market condition accepted as normal by the community. This can be met only by reference to a historic situation which can be accepted as normal.

\section{A. Two Approaches to Historic Definition of Normalcy}

Definition of normalcy by historic precedent can proceed in at least two significantly different ways. One way is to accept as normal the conditions prevailing during a specified period. It is virtually certain, however, that no period can ever be found that will be acceptable as a fair standard of normalcy for all industries. Thus, exceptions will have to be allowed, and some standards of judgment are needed to determine when such exceptions should be made.

In order to determine whether a generally applicable base period can be fairly regarded as normal for a particular industry, it is necessary to compare the experience of that industry over a longer period of time with the course of the economy as a whole. Where the generally used base period is found inapplicable, another base period, more normal for the particular industry, must be found through analysis of that industry's history. Since this individually tailored approach might apply in any case, its substitution for a generally applicable base period is a logical possibility.

Conceptually, the tailored definition of normalcy would seem to offer a greater probability of reaching a fair result in each case. This approach, however, stretches the basic notion that past free-market history can be taken to represent normalcy because neither then nor later was it generally deemed abnormal. While such a test of general consensus is meaningful as to the condition of the economy as a 
whole, it hardly can be applied as to the condition of each segment of industry.

In addition, the practical application of the tailored concept of normalcy clearly presents greater difficulty, since it requires the collection and analysis of a greater volume and more varied selection of data. The greater complexity of the considerations involved also will make it more difficult to secure acceptance for selection of a base period tailored to each case than for one universally applied. This would be especially true if a generally applicable base period had already been sanctioned as normal, as was the case in both the war time ${ }^{2}$ and the $1950^{3}$ excess profits tax legislation. ${ }^{4}$

Considerations of this kind resulted in the choice by both OPA and OPS of a single, generally applicable base period for the Industry Earnings Standard. In the case of OPA, the years I936-I939 were selected as the base period; OPS used 85 per cent of the three best of the years $1946-1949 .{ }^{5}$

The choice of OPA took shape only gradually. At first, it was proposed that selection of the I936-1939 base be specially justified in each case (a view which represents what we called the tailored approach). As thinking progressed, this period was accepted as the standard base period, with affirmative justification required only for the use of any other base. ${ }^{6}$ In the formulation of the OPS standard, no thought seems to have been given to the tailored approach. The OPA precedent and the availability of a base period in the I950 EPT laws seem to have led to a matter of course acceptance of the EPT base as the appropriate definition of normalcy in the Industry Earnings Standard.

\section{B. Merits of Uniform Base Depend on Historic Background}

The case for the uniform base period depends on the characteristics of the most suitable period available at any given time. A uniform base would be a relatively poor choice if it required recognition of a great number of exceptions, or if its use tended to defeat the very purpose of the stabilization program.

To be generally applicable as a standard of normalcy, a base period must be long enough to submerge the minor fluctuations in business conditions from year to year. Also, it must not be significantly influenced by conditions as, or almost as abnormal as those of the price control emergency itself. Thus, a period of total war, serious inflation or severe depression would have to be ruled out. Furthermore, a base period must be fairly recent; otherwise comparison with the current situation can

254 STAT. 975 (1940), as amended, 26 U. S. C. $\$ \$ 710-783$ (1946).

${ }^{3} 64$ StAT. II37 (r95I), as amended, 26 U. S. C. $\$ \$ 430-474$ (Supp. r952).

'Use of a base period specified for EPT greatly strengthens the contention that normalcy is judged on the basis of community consent; for, in this case, consent has been specifically expressed by the Congress. This helps greatly in obtaining acceptance, especially from the Congress and the courts.

"Congress had stipulated 85 per cent of the three best years on the ground that this represented the same profit level as the simple average of all four years for the average of all industries but permitted a more equitable distribution of the burden. Certain industries had been especially seriously affected by reconversion difficulties in 1946 and cercain others by the inventory adjustment recession of 1949 . It, therefore, seemed fair to allow each industry the exclusion of its poorest year.

'See Dickerson, The Industry Earnings Standard, in Problems in Price Control: Pricing Standards, Gen. Pub. No. 7, OPA Historical Reports on War Administration 27, 34, 38 (1947). 
neither be conceptually justified nor statistically implemented, since comparable data can rarely be developed for more remote years.

All these conditions were met by both the OPA and OPS base periods. However, each of these two periods was the only one that could have been selected. For OPA to go back beyond 1936 would have involved the use of abnormal depression years, or else the use of data about fifteen years old. Similarly, OPS certainly could not use the totally abnormal war years and its only other choice was the same period OPA had employed-a period which, by 1951, was also too long past and had certainly lost all attributes of normalcy for comparison with post-war years.

With only one eligible period available, the desirability of using a generally applicable base period depends on the comparison of conditions during that eligible period with those to be expected under price control. In this respect, the OPS situation was entirely different from that of OPA and the situation of any future price control program might again be different in this very significant respect.

While the immediate pre-war years could be called normal by comparison with the war period, business conditions generally were those of a no longer severely depressed, but still substantially under-employed economy. Consequently, direct and indirect war industries working at capacity, and those civilian industries that could be allowed access to resources sufficient to satisfy their share of civilian demand, had the benefit of a much higher level of output to offset substantial increases in factor costs. Absorption of factor cost increases could, under these conditions, continue for some time before it would reduce unit profits, and even longer before it would reduce return on invested capital. Once that corner was turned, there would be still some way to go before the sharply increased returns would be reduced far enough to pierce the level of the pre-war period of under-employment which served as a standard of normalcy.

\section{Potential Dangers of the OPS Base Period}

The post-war base of OPS, in contrast, was for the most part a period of nearly full employment of all resources. True, some industries were idle during the reconversion period which lasted through much of 1946 , and a substantially milder degree of under-employment was experienced during the inventory recession of 1949. But few industries were affected in both 1946 and 1948 and the least favorable year, whichever it was, was excluded from consideration under the terms of the Industry Earnings Standard. Thus, in effect, the base period was almost entirely characterized by high levels of demand, resource employment, prices, and profits-indeed the highest levels in the country's history, except for the still higher levels experienced during the war only by the producers of war materiel and closely related products. Added demand, therefore, did not so readily and widely yield significant leeway for absorption of higher factor costs as it did during the war. Unit profits tended to be affected sooner and returns on invested capital almost simultaneously. Once the profit decline started, it did not have far to go before it hit and pierced the base level of the Industry Earnings Standard. 
It must not be forgotten that OPS, like OPA, might have been forced to administer price control over a prolonged period of total war, and no one could be sure early in $195 \mathrm{I}$ that this would not happen. In that case an Industry Earnings Standard based on the three best years between 1946 and 1949 would have proven a weak reed, indeed, even with the 15 per cent discount, for then the relief level set by the standard would have been reached too soon by too many industries, and after that all cost increases would have qualified for complete pass-through.

In a measure, of course, this pattern of events, which fortunately failed to occur, is speculative. However, in some part at least, the conclusion can be supported by an analysis of actual developments.

The failure of the Industry Earnings Standard to provide a solution of the steel case is not here in point. The steel price increase was forced on OPS by other aspects of stabilization policy and administration.

Here in point, however, are the nearly two score of Industry Earnings Standard cases which followed within a few months after the steel increase. A good many of the resulting price increases were granted industries still enjoying very sizable profits-clearly tending to nullify the function of price control as a device for spreading the burden which total war necessarily imposes on the community as a whole. To justify further cost absorption by these industries, other segments of the stabilization program-notably wage control-would, of course, also have to be administered differently. But the point to be made here is that the terms of the Industry Earnings Standard, and especially its choice of base period, would have made it quite difficult to secure the degree of cost absorption needed in a total war, if such had been the problem facing OPS.

Another set of difficulties which OPS might have encountered because of the characteristics of its earnings standard base period was averted by the development of soft markets in 1951. Some of the industries thereby affected had an extremely favorable profit experience during 1946-1949. When they faced the 1951 drop in demand, any request for ceiling price increases became useless. This relief provided for OPS by the softening of markets was not accidental. The industries with the most favorable profit experience in the base period were largely those whose volatile prices readily respond to high demand even while they are able to supply a sharply increased volume of output. These characteristics made the immediate post-war period exceptionally profitable for these industries and also affected them during the speculative boom of $195^{\circ}$. Once it became clear that this boom was not going to be sustained by the income inflation of a full-scale war economy, some factor costs began to decline, markets began to soften, and ceiling price relief became academic. Had demand pressure continued as in wartime, neither world market prices for wool nor textile wages would have declined. Instead, OPS might soon have been faced with the alternative of raising prices or going into battle for the contention that the unusually favorable base period experience of the textile industries, and some others, was so abnormal as to justify use of a different base period. 


\section{The Problem of Abnormally Favorable Base Periods}

When OPS officials started work on the development of the Industry Earnings Standard, they gave considerable thought to the problem of abnormally favorable base periods which had never arisen in the experience of OPA. The base period provision of the OPA standard was modified only by the phrase: "unless the experience of the particular industry during these years is clearly shown to have been materially different from the experience of industry generally." It was generally understood that such a showing was to be made by the industry applying for relief and that such a showing, of course, would be attempted only when base period profits were alleged to be abnormally low. This in fact was the OPA experience ${ }^{7}$ and it was in accord with the economic conditions during the OPA base period described above.

In contrast, the OPS policy document on the Industry Earnings Standard-Price Operations Memorandum No. 25-dealing at somewhat greater length with base period abnormalities, made an effort to take account of abnormally favorable base periods as well.

After some initial discussion within the Office of Economic Policy two alternatives were proposed. The details of these proposals varied during the course of discussions but their basic notions may be represented by the following formulations:

I. The base period rate of return might be regarded as abnormally high where it exceeded that of three out of any four consecutive years since, say, 1925, including the war years, and exceeded by more than 25 per cent the best such period excluding the war years. It might be replaced by the average rate of the three best war years or by 125 per cent of the average of the three best of any four consecutive pre-war years.

2. The base period rate of return might be regarded as abnormally high where it exceeded 160 per cent of the average rate for 1938-1948, and 125 per cent of the 1938-1948 return might be substituted for 85 per cent of the standard base period.

The second of these alternatives was the reciprocal of the I950 EPT relief provision which permitted a company whose excess profits tax credit was less than 63 per cent of the 1938-1948 average to substitute 80 per cent of that average. The proposal was based on the assumption that the earnings standard for industries with abnormally low base period profits might use this EPT formula so that the use of the reciprocal formula for industries with abnormally high base period profits could be readily justified. The simple precision of the EPT provision was regarded as a most valuable feature, although it was recognized that some modifications might be necessary for price control purposes. The rationale of the alternate proposal stated first above is no longer readily determinable.

Both proposals were discarded mainly because it was recognized that reference to pre-war periods would cause serious difficulties both in applying the standard and in getting acceptance for the results. Instead, the Economic Advisor suggested

\footnotetext{
${ }^{7}$ See Dickerson, supra note 6 , at 65 et seq.
} 
the simple solution of allowing a minimum return of to per cent and a maximum return of 25 per cent on current net worth. While admittedly arbitrary, these figures appeared to be sufficiently generous and plausible to provide an easy solution of the problems of both abnormally low and abnormally high base period earnings.

The arbitrary substitution of a minimum return of to per cent for an abnormally low base period return was readily accepted. The substitution of a 25 per cent maximum for an abnormally high base period return, however, was vigorously opposed as too arbitrary. It was finally replaced by a paragraph of POM-25 which left it to the operating divisions to determine when a base period return was to be regarded as abnormally high and to recommend some appropriate adjustment to the Clearance Committee. Operating officials received no further guidance beyond the instruction that they should "in such cases, obtain earnings data for a longer period, if possible back to I935." If any industry with an abnormally high base period return had applied for relief, this provision could, at best, have formed the starting point for a fresh effort to tackle the problem it was supposed to have solved.

\section{E. The Terms of Choice}

When a price control agency adopts an Industry Earnings Standard for hardship relief, it implicitly undertakes to determine the fairness of ceiling prices through measuring the fairness of profits by reference to historic experience which is accepted as normal.

It can then attempt to satisfy the requirement of normalcy by adopting a standard base period, with a more tailored approach reserved for exceptional cases. That was the choice made by OPA and OPS. An alternative would be to use a tailored approach in every case. This approach would require the development of rules for determining the normal profit level of an industry on the basis of its own experience. In some small measure, the experience of OPA with exceptional cases and the thought given in OPS to abnormal base periods may help in developing such rules-either for the tailored approach to all cases or for the handling of the exceptional ones that do not fit a standard base period.

The choice between the two approaches should be based on an analysis of their merits in the light of the economic conditions expected for the period of price control and those prevailing during the preceding years. Hindsight seems to reveal that during World War II these conditions were unusually favorable for the operation of an Industry Earnings Standard with a uniform base period. They were far less favorable for the repetition of this procedure by OPS, and that repetition would have tended to defeat the purpose of price stabilization, if total war had ensued during the agency's life.

The crux of the problem is the need for cost absorption as a brake on the inflationary spiral. Absorptive capacity is greater when the level of industrial activity is higher during the control period than it was during the "normal" base period. If the "normal" level is so high that even a war effort can raise it but little, spiralling 
inflation can be avoided only to the extent by which the stabilization program succeeds in keeping cost factor prices from rising. But complete, or nearly complete stabilization of such cost factors as farm products, imported commodities, and labor is a very tough assignment indeed (even with the use of subsidies which helped OPA in this respect).

If a stabilization program has to be imposed at a time when every usable standard base period was characterized by very high industrial activity, the question arises whether the tailored approach is more promising. It would be so if (I) it were found possible to devise and make acceptable a set of rules which excluded the most, as well as the least profitable years of each industry from the "normal" base, and (2) it were found impossible to apply similar rules, or an equivalent discount of the highest prosperity profits, to a standard base period for all industries. The tailored approach to all cases, rather than exceptional ones only, might also be indicated when the agency must anticipate a good many cases in which it might be forced to insist on a departure from its standard base period.

Of course, if the tailored approach is chosen, considerations similar to the terms of that basic choice must be faced in writing the basic rules for it and in applying them to each case. But adoption of a standard base does not completely obviate such individual decisions. Explicitly or implicitly, a choice is made in each case, whether the standard base is accepted as normal or an exceptional one substituted.

In making these choices, be they concerned with basic policy or individual application, it will not be sufficient to analyze the prospective consequences on the basis of economic conditions alone. It will also be necessary to consider the practicability of administrative execution (including, e.g., the availability of data and the complexity of procedure) and the acceptability of results to the preponderance of community judgment. On the other hand, it will be wholesome to keep in mind that the choice of a base period is only one element in Industry Earnings Standard formulation and application. If that choice tends to bias the result in one direction, that bias may at least in part be offset by other decisions, provided it is not too large-and it is clearly recognized.

\section{II}

\section{The Definition of Industry}

"Industry" is an elusive concept and its definition gave rise to as many disagreements and difficulties as any other problem encountered in the operation of the Industry Earnings Standard, by either OPA or OPS. The question therefore arises whether this concept is not dispensable.

Normalcy may be justifiably attributed to the condition of the economy as a whole during some designated period. It certainly cannot be attributed, even for such a period, to the cost and price of every single product or the profit position of every single firm. If any of these are ever "normal," they certainly are not all normal at the same time. Consequently, to base a relief standard on "normal" profit 
for each product or each firm, would fly in the face of any concept of normalcy based on reference to past experience. In fact, it would impose a drastically abnormal pattern on the economy.

The purpose of price control itself also would be violated by a basic standard using the individual product or the individual firm as its starting point. Permitting a normal profit on each product or for each firm would clearly result in a sharp increase in total business profits and in their share of the national income-an increase that could never be reconciled with any reference to normalcy.

The basic relief standard, therefore, cannot start with the individual product or the individual firm as its point of departure. It must use some grouping that has a reasonable resemblance to those groupings which normally affect profitability.

A. Homogeneity of Exposure to Cost and Market Conditions

Essentially, fairness and equity require that sellers have approximately the same chance of profitability, one relative to the other, as they do in normal times. Each seller's chance of profitability depends on his cost and market conditions. Ideally, therefore, the proper grouping is that of the sellers who are exposed to the same cost and market influences. The most appropriate definition of "industry" for the purposes of the earnings standard, thus, would be to say that an "industry" is a group of sellers which is homogeneous in regard to their exposure to cost and market conditions and changes in these conditions.

If the homogeneity required by this definition is taken with a grain of salt, the definition comes reasonably close to a use of the word "industry" in common parlance. The grain of salt is necessary because the complexity and diversity of real life in the economy never permits the existence of homogeneity in the full sense of the word.

The definitions of "industry" used by OPA and OPS never sharply focused on this basic concept of homogeneity of exposure to cost and market conditions. While it might have been useful to refer to such a basic formulation, it does not seem to have been suggested. In any case, it would have been necessary, for practical purposes, to use more descriptive terms in clarifying the intended definition. The terms actually used were entirely of that kind, but most of them at least suggest some homogeneity of cost and market conditions.

OPA referred to such considerations as basic uniformity of the manufacturing processes, use of the same raw materials, and general similarity among the products. OPS instructions on "Industry" definition in POM 25 referred to an industry as "a group of firms with certain common characteristics which set them off from the rest of the economy. These common characteristics relate to the products-and the assortment of products-which they make, or to the materials, manufacturing processes, or marketing methods which they use."

OPS instructions specifically recognized that in defining an industry, an area of discretion and judgment must remain. In exercising this discretion, the following guides were to be followed: 
(I) An industry typically makes related products, from the same general kinds of raw materials.

(2) Ordinarily there is a basic similarity in the manufacturing processes. On the other hand, variations are to be expected in stages of technological advancement, degrees of integration, style of product, and specific end uses, as well as the method of marketing.

(3) An industry usually makes a wide variety of products; a single line industry tends to be the exception rather than the rule.

(4) The industry should not generally be so narrowly defined that a substantial number of its firms fall within another industry as well.

(5) On the other hand, the industry should not be so broadly defined that it includes two substantial groups of firms, each group with common characteristics of its own, but with nothing in common with the other group, merely because some large firms have something in common with both groups. (E.g., because several large automobile producers are also important in the production of refrigerators, automobiles and refrigerators should not be considered as one industry.)

The "guides" (rather than rules) clearly reflect the difficulty. The first of them, in referring to the products of an industry, requires that they be "related" rather than the same, and further modifies this requirement by the word "typical." It does not say that the raw materials are typically the same, but only that they are of "the same general kinds." The second of the guides stipulates merely "basic similarity" in the manufacturing process; it is not satisfied with saying that this is only "ordinarily" present but specifically emphasizes that variations are to be expected in a variety of respects. The other three guides also include similar indefinite statements and modifications. How then could operating officials use such instructions in defining an industry?

\section{B. Close Relation to Basic Stabilization Policy}

The fault does not lie with the instructions. They accurately reflect the basic fact that there are no objective criteria for dividing the nation's business firms into indisputable "industry" groupings. The economy is not so organized as to permit the drawing of such clear-cut lines. It is an error to believe that the problem can be solved by "the informed judgment of persons familiar with trade understanding and the actual functioning of particular business groups," as an earlier appraisal implies. ${ }^{8}$

The answer cannot be found in some particular concept of industry but only by examining the purpose to be served by the definition. The Industry Earnings Standard is designed to draw a line between cost absorption and price relief. When is it "generally fair and equitable" to require absorption and when must relief be granted? This is a question that can be answered only with a view to basic stabilization policy. The definition of industry is part of that answer, for relief applications will be made only with respect to products that seem to yield sub-standard profits; if these products are segregated by a narrow industry definition, less cost absorption will be required. Under a policy which lumps many more product lines together

\footnotetext{
${ }^{8}$ See Dickerson, supra note 6, at 50.
} 
under a broader definition of industry, more absorption will be required and fewer price increases granted.

The practice to be followed in defining an industry, therefore, is a matter of basic stabilization policy. A rigid "hold-the-line" policy will require more cost absorption and therefore broader definitions of industry. Less absorption and narrower definitions of industry are appropriate to a policy designed merely to put a slight brake on the expression of inflationary pressure in price and wage levels. Fairness and equity of the policy to be followed in defining industry not only require even-handed application of absorption policy as between industries; it also requires even-handedness as between industrial profits and other shares of the national income.

For purposes of practical administration, instructions for the definition of industry cannot be framed in these terms. It is necessary, instead, to use concrete indications such as the guides of POM 25, but to leave them sufficiently flexible to accommodate whatever degree of cost absorption appears appropriate under the stabilization policy of a given period. Those responsible for shaping the course must be governed by over-all national policy considerations. They will not be afraid of industry criticism at a time when industry itself can reasonably be expected to accept limitation of profit opportunities as no more than consistent with the sacrifices imposed on other segments of the community. On the other hand, they will tend to apply a more lenient policy (and therefore narrower definitions of industry) at a time like the latter half of 1952 , after the wage and price decisions in the steel case; then, the community and the Congress were inclind to agree with industry that rigid cost absorption requirements could hardly be defended as fair and equitable.

Once these policy decisions are made, price control officials face the problem of their transmission from the policy making to the operating level. They may be conveyed as part of a general policy understanding throughout the agency. When the director of the agency can feel sure that such uniform understanding exists, he can readily leave the problem of defining industry to operating officials with a minimum of check or supervision. On the other hand, the definition of industry in each case will have to be made subject to approval of policy making officials at a time when no such uniformity or understanding exists. That is often so immediately after a policy change; some time is required to establish understanding of a new policy throughout the agency, and the application of that policy to specific cases is the principal and most effective means of making the new policy understood.

This was reflected in OPS experience. Shortly after the application of the Industry Earnings Standard got under way, it was realized that operating officials tended to use industry definitions which, in their effect, required much less cost absorption than was appropriate under then existing policies. Consequently, their definitions were made subject to approval of the Clearance Committee at an early stage of the proceedings in each case. Later on, the authority for defining an in- 
dustry was returned to operating officials. By that time stabilization policy had changed and the definitions which these operating officials were inclined to consider appropriate were actually in accordance with policy. Moreover, the exchange of views involved in the earlier clearance procedure, and also in the preparations for handling a larger volume of relief applications under the standard, had served to develop effective understanding between the policy making and operating levels.

\section{Relation to Earnings Standard Administration}

Having noted that the definition of industry partly depends on stabilization policy, it must also be recognized that this definition is only one part of a package. It is only one among several factors which determine the answer to the relief application. A number of the other factors likewise defy indisputable, precise definition. Even within the framework of a given stabilization policy, therefore, an unfair decision might result unless all these factors are considered together in arriving at a judgment. If every judgmental decision is such as would achieve maximum cost absorption, the total result may be unfair even under a rigid "hold-the-line" policy. Similarly, even under a flexible policy, unfairness to the buyers may result if every judgment favors the seller. It is not, therefore, the definition of the industry, considered by itself, that is to be attuned to basic stabilization policy of the time; it is rather the composite of all the judgments involved in drawing the conclusion from an earnings standard study.

This works in reverse, too. Definitions of industry are necessarily subject to many practical considerations. The group which is recognized as an industry must be such as to permit the compilation and analysis of the data required in an earnings standard case-unless, that is, the definition of industry is made merely for the purpose of making clear that no relief is indicated. These practical considerations of data collection and analysis, therefore, may sometimes lead to a narrower definition of industry than would be thought appropriate in the light of stabilization policy. Unless the gap between the proper and the practical definition is too wide, this kind of deviation from current policy can perhaps be offset by applying stricter yardsticks in other judgments to be made in the course of analysis. A relatively narrow definition of industry might indicate that at other junctures doubt must be resolved in favor of absorption rather than relief. On the other hand, had a broad definition of industry been applied and thus a bias against relief been introduced, other doubts might be resolved in favor of the applicants for a higher price.

The lesson is clear. It is a mistake to believe that an objective definition of industry is possible, and any procedure relying on this assumption would inevitably lead to unintended results. These can be avoided only if price control officials face with open eyes the fact that a definition of industry involves a judgment; that this judgment must be related to other judgments made in the course of an earnings standard study; and that the total result must reflect that concept of fairness which is appropriate to stabilization policy at the time. 


\section{III}

\section{The Multi-line Problem}

The relief application under the industry earnings standard is typically concerned with a reasonably homogeneous group of related product lines. The manufacturers of these lines, however, or at least some of them, usually carry other product lines more distantly related or entirely unrelated to the lines for which relief is asked. Presumably, these other lines are more profitable; for, otherwise the relief application would extend to them as well. The question, therefore, arises whether the greater profitability of these lines can in fairness be allowed to affect the relief to be granted for the less profitable products.

Where the entire business of all producers concerned is characterized by homogeneity of exposure to cost and market conditions, no special problem arises, even though their particular production programs show wide variance and extend beyond the lines for which relief is requested. The very nature of the Industry Earnings Standard requires that the total earnings of the entire industry be taken into account, and the breadth of the industry definition is subject merely to the considerations previously discussed. The multi-line problem comes into play when some, or perhaps all the companies concerned derive a significant part of their profits from product lines exposed to clearly heterogeneous cost and market conditions. Before the significance of that situation for earnings standards administration can be discussed, it is necessary to analyze the reason for its existence.

\section{A. Diversification and the Earnings Standard}

The multi-line problem arises essentially from the wide product diversification of many companies. Industrial diversification is no different from the diversification practiced by investors in securities or in real estate and is adopted for the same reasons-principally, the desire to reduce business risk. Accepting the inevitable prospect that at any given time some of its products will yield little or no profit, a company tries to offset this disadvantage by dealing in a variety of products in the hope that they will not all be in an unfavorable profit position at the same time.

For obvious reasons, a company will normally extend its operations first within an area characterized by common or closely related production requirements (and consequently cost conditions), or one directed to the same market or closely related markets. Large enterprises, however, and also some small ones, may go considerably further in their effort at reducing risk of diversification. They may deliberately seek out fields of activity exposed to widely differing cost and market conditions, because these very differences may appear to involve a greater assurance of stability in the profits of the company as a whole.

Thus, diversity of industrial production programs is closely related to the very profit experience with which the Industry Earnings Standard is concerned. It is part of the market conditions to which producers are always exposed. In a competitive market, the prices of a single-line producer are normally affected by the fact 
that his multi-line competitor is engaged in some unrelated business. Multi-line companies may make special production and price decisions for each of their product lines; but these decisions will not be unaffected by the profitability of their business as a whole and by the financial strength derived from their entire operation, since the very purpose of their diversification is to strengthen their over-all market position. The single-line producer who competes with a multi-line company is aware of the fact that he may at times be unable to raise his prices because his multi-line competitor can better afford to sell at a narrow margin. At other times, he may be able to sell at a higher price, as the situation is reversed. Thus, it is normal for him to find his price held down (or held up) merely because cost and market conditions are more favorable (or less favorable) in a business which is strange to him but in which his multi-line competitor is engaged.

In as much as the presence of multi-line producers and the greater profitability of their unrelated product lines is a normal condition of the market, it is not unfair to let this greater profitability have some effect on price relief decisions. It is a reasonable presumption, therefore, that the administration of the Industry Earnings Standard should take into account the profitability of the entire business of all the companies engaged in a particular industry. This is a presumption rather than a firm conclusion because it must also be recognized that this procedure can in some cases lead to untenable results. Where the industry concerned is only a small segment of the business of multi-line producers, and where the difference between the profitability of that small segment and of the rest of their business is great, it may indeed be unfair to give any weight to the rate of return of the multi-line companies as a whole. In this case, it would not be normal for the multi-line companies to set prices for that small segment of their business at a level far away from that indicated by the cost and market conditions of the products directly involved.

\section{B. Determining the Appropriate Procedure}

The conclusions just reached, if expressed more precisely, may form the basis of a practical procedure. A price control agency will encounter a wide variety of multi-line problems, ranging from those in which there is no unfairness in considering total earnings of all companies in the industry, to those where this would lead to clearly unfair results. A combination of three factors determines the position of each case within this range: (I) the share of the multi-line companies in the sales of the products concerned; (2) the share of the products concerned in the sales of multi-line companies; and (3) the difference in profitability as between the products concerned and the other business of multi-line companies. The smaller the first two of these factors and the larger the third, the greater is the probability that an unfair decision will result from taking total earnings of multi-line companies into account.

The current relationship of the multi-line companies to the industry seeking relief is the proper starting point. Still more important are any changes in that relationship which may have occurred between the base period and the time of a relief ap- 
plication. If no significant change has occurred in any of the three points mentioned above, no unfairness is involved; for, in this case, their influence on current return is no different from their influence on base period return, and it is the comparison between these two which determines the relief decision. If, however, the unrelated business of the multi-line companies has gained more in volume and profitability than the product lines in question, then lumping all earnings together is much more likely to result in an unfair decision.

Thus, it is clear that the three above-mentioned statistical criteria can help in determining the appropriate procedure and that focusing on changes since the base period is especially in order. It also seems clear, however, that no precise borderline can ever be drawn between the cases where consideration of total earnings of multiline companies is fair and those where it is not. True, some cases will unquestionably fall on one side, some on the other. Within the intermediate zone of uncertainty, however, the decision has to be made with two questions in mind: ( $I$ ) Is the stricter or the more lenient approach in better accord with current stabilization policy; and (2) what is the alternative course of action and its consequences?

Where the multi-line producers supply only a small portion of the products under consideration, a convenient alternative is available. Their earnings may be disregarded in the computation made under the Industry Earnings Standard, although the decision arrived at will apply to them as well as the single-line producers. Where the share of the multi-line companies is too large to make this procedure acceptable, the choice is far more difficult. The only alternative to using total earnings is a segregation of profits derived by multi-line companies from the products under consideration and of the net worth imputable to this line of activity.

\section{Segregation of Profits and Net Worth}

Severe difficulties are met in determining profitability of one segment of a multiline business, and before such a segregation of multi-line company accounts is undertaken, certain hazards should be understood. The errors that may result from segregating profits, and especially those that may be incurred in segregating net worth, may well be greater than the errors that could result from taking the total return of the multi-line companies. Moreover, the direction of error involved in taking total profits is known and its size may be statistically estimated and thus can be taken into account. By contrast, in segregating profits and net worth, neither the direction nor the size of error can be known.

Furthermore, it must be recognized that segregation of earnings and net worth is inevitably time consuming. The disadvantage to the industry resulting from delay may be more serious than the difference in the amount of relief eventually granted. The cost of delay can be estimated. It may not be possible to estimate at the start the possible difference in the amount of relief but it certainly can be done as soon as separate figures have been obtained for single-line companies on the one hand and the total business of multi-line companies on the other. 
Thus, it is possible to determine whether earnings and net worth segregation is worth while. In view of the hazards involved, it should be undertaken only when an appraisal of total earnings indicates that a fair conclusion cannot be reached without segregation. The delay entailed by this extra step need not harm the industry. It can and should be given interim relief on the basis of total earnings before the accounting work on segregation is started.

An exception may be justified where segregation happens to be easy because segregated accounts have regularly been kept right along. In these cases, however, it must not be overlooked that such accounts are conclusive only where the segregation is as complete as it would be if fully separate businesses were involved-a condition that rarely exists.

Finally, some reference must be made to an additional source of doubt as to the fairness of looking at total profits of multi-line companies. As a rule, the multi-line producers are large companies and the single-line producers are small ones, at least by comparison with each other. This leads to the impression that small business is placed at a special disadvantage and that the result cannot be fair because large profit figures of the big companies are given an unrealistically heavy weight. This argument combines two different and separable considerations, one merely a matter of statistical technique and the other more fundamental.

As a matter of statistical technique, it is not only unnecessary but improper to give the same weight, dollar for dollar, to the profits of the large multi-line companies and those of the small single-line producers. In determining the average rate of return for the industry, the weight assigned to each producer should correspond to that producer's share in the industry concerned, excluding the outside business. Thus, the rate of return of the multi-line companies need not and should not be given a disproportionate weight in computing the industry average.

The more fundamental aspect is in the implication that, since the single-line producers are relatively small, it is particularly unfair to have their profitability impaired merely because their competitors are engaged in other more profitable lines. This emphasis on smallness tends to distract from the fundamentally relevant fact that all single-line producers are normally exposed to different market conditions where they are in competition with multi-line companies. The emphasis on smallness does not change the significance of that fact. Nor is smallness necessarily a valid consideration in its own right. It is valid only in so far as small business is less profitable. That, of course, is sometimes true but by no means always, especially when "smallness" is present only by comparison with the total business volume of multiline enterprises. The very co-existence of single-line and multi-line companies side by side would suggest that single-line companies are not necessarily in a weak competitive position.

IV

The Method of Earnings Comparison

No matter how an industry standard may be constructed or administered, it 
must always involve a comparison of current earnings with those of a period presumed to be normal. This requires the relation of profits to some base. Profit is measured for some purposes as a percentage of sales; for others as a percentage of capital, defined in any one of several ways. Each of these several kinds of measurements is meaningful in appropriate context and the choice between them depends on the context. The present discussion is concerned with the choice of a basis for the comparison of earnings required by the Industry Earnings Standard.

The various bases to which earnings can be related, of course, are not independent of each other. When one industry's sales are twice as large as its net worth, while another industry's sales are four times its net worth, it is very likely indeed that the industry with the higher capital turnover will earn a smaller percentage on sales. If these relationships of sales to net worth were stable over time, it would in fact make no differences which of the two was chosen as a basis for comparing current and base period earnings. If the ratio between sales and net worth remained the same, an industry earning 5 per cent on sales and ro per cent on net worth during the base period would be entitled to the same amount of relief whether the comparison was based on earnings as a percentage of sales or on earnings as a percentage of net worth. In reality, however, these ratios do not remain stable. The divergence in trend of sales and net worth since the base period is relevant to stabilization, and an understanding of that divergence must precede the choice of a method of earnings comparison for the Industry Earnings Standard.

\section{A. Earnings as a Percentage of Sales}

To start with, we may analyze the use of sales as a basis of comparison, because it has the advantage of greater simplicity. There is usually less difficulty encountered in determining sales volumes than in determining profits. It is relatively simple to compute the relationship of profits to sales and compare the current ratio with that of the base period. It is certainly easier than any comparison involving invested capital. The propriety of the simpler method depends, however, on how it influences the result.

It may be taken for granted that a period of inflationary pressure is one of unusually great business activity. That this is not necessarily true for all industries must be recognized, and the implications of that fact will be discussed later on. In the generally prevailing situation, however, industry will make more complete use of its productive capacity during the price control period than it did during the base period (unless the earlier period was one of maximum production, which fact, as previously explained, would throw serious doubt on its suitability as a base period). More complete use of capacity increases profits proportionately more than sales, because certain costs will not rise at all and others will rise less than the volume of output. Indeed, the cost reduction because of larger sales is frequently regarded as a proper basis for price reduction when the sales increase is achieved by broadening a company's or industry's market rather than by inflationary pressure. In this case, the industry shares the benefits of larger production with its customers. 
Price controllers, then, must assume that such benefits of larger volume are available during the control period. The question is whether fairness and equity require that sellers be conceded a vested right to the full amount of these benefits. If not, sound stabilization policy will at least deny price relief until cost increases have offset the benefits of larger output.

This is the choice between adopting or rejecting sales as the basis for earnings comparison. If the percentage of sales earned during the base period is accepted as the standard of comparison, industry is conceded a vested right to whatever benefits are derived from fuller use of its capactity. On the other hand, if the standard of comparison is some financial measure of capacity itself, industry will be entitled to a higher price only when increases in the price of cost factors have absorbed more than the benefit from fuller use of capacity.

The question of fairness and equity here involved cannot be decided without reference to the cause of the increase in business volume. Of course, the increase might have occurred as a result of normal economic developments. In fact, however, conditions of the emergency price control period are certain to be those of war or some similar national emergency. That emergency itself is bound to be the predominant, if not the sole, cause of the high level of business activity. With price control established to spread the burdens of the emergency, it certainly should not concede a vested right of industry to benefits occurring solely or predominantly because of the emergency. With sales rising faster than capital investment, the use of sales as the basis of earnings comparison would result not only in more rapid price increasesbut in increases incompatible with the purposes of price control.

This becomes even clearer when attention is focused on the differential results for specific industries. While industry in general is bound to experience a greater increase in sales than in capital investment, the experience will not be the same for every specific industry. If earnings are related to sales, the greatest benefits will go to those industries whose sales volume has been most increased by the emergency -notably the suppliers of war matériel and related industrial equipment. This clearly would not be in keeping with the purposes of price control. The unfairness would appear to be particularly great when shortage of materials or labor required that some industries be held below full productive capacity in the face of demand for capacity output. This simply points up the basic reason why the ratio of profits to sales is an unsuitable method of earnings comparison.

\section{B. Total Capital or Net Worth?}

Once the ratio of profits to sales has been rejected as the basis of comparison in favor of some ratio of profits to invested capital, the question arises how invested capital should be defined. The narrowest possible definition is "net worth"-the total of all accounts which represent the equity of the owners. The broadest possible definition would include all funds working in the business-ownership equity and all indebtedness alike. A more popular suggestion has been to include ownership plus funded indebtedness, but to exclude short-term indebtedness. The 
most important distinction, however, is between a definition confined to ownership equity and one that would also include debt, whether all kinds of debt or funded debt only.

The choice between the broad and narrow definitions presents a problem quite similar to that of choosing between relating profits to sales and relating them to invested capital. The nature of an emergency period makes it virtually certain that the increase in total capital will be larger than the increase in net worth. With business activity at a higher level, more working capital is required and that need is more likely to be met by borrowing short-term funds than by increasing equity, especially when the need has arisen relatively recently and appears to be temporary. There is less certainty that the proportion of funded debt to total capital will also be increased. It is likely, however, that in those industries whose output rises the most because of the emergency, new capital needs will in substantial measure be met with some form of government assistance, which frequently increases funded indebtedness.

Consequently, it might be said that the proportional increase from the base period to the time of price relief will be greatest in total capital employed and least in net worth, with the combination of net worth and funded debt in between. Price increases, therefore, will be largest if the historic relationship of profits to total funds is used as the basis of comparison; they will be smallest if net worth is used; and the use of net worth plus funded debt should lead to an intermediate result. It being the purpose of price control to minimize price increases, the use of net worth is clearly indicated. This conclusion, however, could not stand unless also consistent with considerations of fairness and equity.

In order to test their fairness, we must analyze the economic significance of the different methods of comparing earnings. Over a long period of good years and bad ones combined, equity capital generally receives a higher average return than loan money. In years of low business activity, equity capital, receiving only a residual share, may obtain only a small return, or even suffer a loss. Its compensation is all the higher in years of high activity, when total profits leave a much larger residual after the payment of fixed charges. Therefore, the mere fact that the emergency period yields a high return to equity capital is not of itself objectionable.

A somewhat different light is thrown on the problem, however, by the fact that the high level of business activity characteristic of the price control period is solely or predominantly the result of an emergency. The special benefit reaped from the employment of additional loan capital thus is a result of the emergency itself. Price control, set up to assure fairness in sharing the burden of the emergency, consequently should regard the benefits resulting from employment of additional loan capital as funds available for cost absorption.

Using net worth in earnings standard administration does not imply price reductions when the rate of return exceeds that of the base period, as it usually does for a significant period of time before cost increases absorb the additional profits resulting 
from increased activity. During this period the owners of industry enjoy the benefits resulting from operation with borrowed money. It is only after cost increases have absorbed these benefits that the question arises whether prices should be raised to allow industry its base period rate of return on all capital employed or on net worth only. Thus, the same reasons which indicated the use of invested capital rather than sales as the basis for earnings comparison, also stand in favor of using net worth only rather than including any indebtedness.

Similarly, fairness and equity as between different industries point to the same answer. The inclusion of indebtedness would be most favorable to those whose ratio of indebtedness had risen the most from the base period to the time of price relief. It would be reciprocally unfavorable to those industries who had placed greater emphasis on equity financing during the same time. The industries most likely to have used a greater proportion of borrowed money are those whose output is most in demand because of the emergency. For reasons previously discussed, it would not be appropriate for price control to favor these industries in the name of fairness and equity. (It may have to raise their prices beyond the level indicated by fairness and equity where stimulation of essential supplies is involved; but this is another matter.)

Thus, as a matter of general principle, the rate of return on net worth emerges as the best method for the comparison of current earnings with those of the base period. This is valid only as a matter of general principle-because one reservation must be made. The circumstances of an emergency period, and the changes in economic conditions since the base period, are likely to be those assumed in the analysis above. They were actually so in the OPA and OPS experience. But it can perhaps not be taken for granted that they will always be the same. Consequently, during each price control period, it is necessary to examine how the capital structure of industry in general has changed since the base period.

\section{Adjustment for Price Increase?}

Apart from the base to which earnings are related, critics of the earnings standard have suggested that it is unfair to imply a constant value of the dollar. The argument has taken several forms. It was, for instance, expressed by a representative of the steel industry as follows: ${ }^{\ominus}$

It is my considered recommendation that the earnings standard . . should be amended ... to give effect not only to the increase in invested capital of the industry but also to the need for more dollars of income to accomplish the same results as a smaller number of dollars would have accomplished in the years of the base period. In other words, a cost-of-living increase provision should be adopted for the use of industry as well as for the use of labor.... It is my thought that, because of the depreciation in the value of the dollar, and in order to establish equitable earnings standards, the dollar earnings for the 3 years selected from the $1946-49$ period should be adjusted by the increase in the wholesale-price index up to the present time.

\footnotetext{
${ }^{\circ}$ Letter from Ben Moreell, President of the Jones and Laughlin Steel Corporation, to Roger L. Putnam, Administrator, Economic Stabilization Agency, Mar. 15, 1952.
} 
A closely related point was also made by the same industry and by others who have emphasized that both capital accounts and depreciation charges are based on bookkeeping entries made throughout the life of a corporation, many of them in dollars of much greater purchasing power. Because of the effect on depreciation charges, costs are understated and profits overstated; also, net worth is understated and, therefore, current profits appear to yield a higher return than they actually do. Since all these points in effect call for adjustment of base period profits to reflect price increases, they are here dealt with together.

At first glance, considerable validity may attach to the notion that it is unfair to allow, say, only one dollar of 1952 value as an offset to a dollar paid out for equipment in $193^{\circ}$ when much more could be bought for that dollar. Economists and accountants, however, overwhelmingly reached the conclusion that depreciation should be applied to original cost. We need not here discuss the reasons for that view since in fact the issue is largely irrelevant to the administration of the Industry Earnings Standard. The standard is concerned only with comparisons between the base period and the time of relief application. Whatever the change in the value of the dollar in all the years prior to the base period, the consequences will already have been reflected in the base period rate of return, and it is that rate which is used as a standard of comparison. Any price increase that occurred prior to the base period, therefore, is without relevance to our problem, and so is its reflection-or lack of reflection-in capital accounts and depreciation charges.

The real issue, therefore, is whether attention should be paid to price increases that have occurred between the base period and the time of relief. It may be held that, apart from all other factors, price increases normally result in a corresponding increase in profits and that this aspect of normalcy cannot be eliminated under price control without imposing unfairness and inequity. That is the gist of the demand for reflection of price increases in earnings comparisons. The argument, however, does not seem in accord with the role of profits in our economy. They are affected by numerous factors, all of which are interrelated. It is the total effect of all these factors that is reflected in profit changes and the effect of price increases cannot be isolated any more than any other determinant of profits. The concept of a cost-of-living increase simply is not applicable to profits.

Moreover, the price increases now in question are those between a presumably recent base period and the emergency period requiring price control. It is very likely, and it was true for OPS, that these price increases are almost entirely due to the emergency itself. It does not seem appropriate for price control to assure to industry higher profits flowing from circumstances of the emergency itself. The reasoning which led to the rejection of sales as a basis for comparing profits is again pertinent here, for the assurance of profits equal to a historic percentage of sales would be very similar to the allowance of an adjustment for price increases, in fact, it would be the same if it could be assumed that the increase in the particular in- 
dustry's cost factor prices was a proper reflection of the increase in the general price level.

Thus, it must be concluded that no adjustment for pricing increases can properly be made in the profit comparisons of earnings standards administration. The basic concept of price stabilization would be violated if price increases were granted for the mere purpose of increasing profits to a level taking account of previous increases in prices. In this fashion, the spiralling character of uncontrolled inflation would be merely duplicated rather than controlled.

\section{Taxes and Accelerated Amortization}

Another criticism against the method of earnings comparison in Industry Earnings Standard proceedings was that it dealt with earnings after taxes and disregarded accelerated amortization permitted for tax purposes on the basis of special certificates issued during both World War II and the Korean period.

The answer to the argument concerning taxes need not elaborate on the following statement made on this subject by Price Stabilization Director Ellis Arnall in his testimony before the Senate Committee on Labor and Public Welfare on April I6, r952:

I should perhaps digress a moment to consider one objection which the industry had made to our Earnings Standard and its application to steel. I am referring to the fact that the standard is based on profits before, rather than after, income and excess profits taxes. I want to say most emphatically that profits after taxes cannot be used as a basis for price control policy.

Congress, in enacting tax legislation, expresses its judgment as to the manner in which the tax burden should be allocated. The tax increases which have been required during this period of emergency similarly reflect the judgment of Congress as to how the added burden of defense costs should be distributed. If the contention of the steel companies were accepted, it would mean that OPS, was, in effect, altering this Congressional decision by permitting certain industries or certain groups of the population to shift their just share of the tax burden to those less able to support it.

By the same token, simple justice would require that personal taxes should be included in measuring changes in living costs and that workers would therefore be entitled to correspondingly larger cost-of-living adjustments in their pay. Similarly, taxes would have to be included as an element in farmers' costs and parity levels would have to be raised accordingly.

If each group in the economy should thus attempt to avoid its share of the burden of mobilization, by shifting that burden to someone else, the only result would be to generate a new inflationary spiral. The economic burden of mobilization will not disappear merely because each group tries to shift it to another. The new result could only be to shift, through further inflation, the entire burden of the defense program onto those individuals and industries who, because of their weaker economic position, were unable to "pass the buck" farther along the line. Since it is these groups in the population which are already suffering most from the inflation which has occurred, the burden on them would soon become intolerable.

In view of these considerations, it is the position of the Office of Price Stabilization that the tax burden should rest where Congress imposed it, and that the agency should 
take no steps which would have the effect of shifting this burden to those less able to support it.

The amortization certificates present a somewhat different problem which must be analyzed in the light of the purpose and operation of this scheme.

The amortization certificate scheme was designed to facilitate the construction and financing of new plants by private industry. Under these certificates the Internal Revenue Bureau permits depreciation deductions from taxable profits in amounts sufficient to write off the new plants within a few years, whereas the Revenue Code would otherwise require that these deductions be spread over the prospective life of the facilities. Thus, the certificates do not change either the total amount of depreciation or the total amount of taxable profits. But they reduce taxable profits during the immediate future and raise them in later years. This shift of taxable profits reduces taxes to the extent to which tax rates during the more distant years may be lowered, and a future lowering of corporation tax rates had been expected ever since their high emergency level (including the Excess Profits Tax) was put into effect.

This prospective tax benefit granted by issuance of amortization certificates could have in no way been affected by price control action, unless ceiling prices had been set so low that taxable profits before accelerated depreciation were less than these charges, which was virtually impossible under the Industry Earnings Standard. (If it had occurred in the case of a highly exceptional company, it might perhaps have been regarded as basis for individual hardship relief.)

Of course, entirely apart from tax considerations, it is more convenient for a company to deduct higher depreciation charges when profits are high, and they would have been raised by an increase in ceiling prices. But increasing depreciation for other than tax purposes is always within the discretion of a company and has nothing to do with the amortization certificates. Some companies make larger depreciation charges than the tax law permits and let the Internal Revenue Bureau tax these charges as profit. However sound such procedure may be, it does not make such additional depreciation charges part of normal cost for price control purposes. The amortization certificates did not change this in any way but merely conveyed a tax privilege. To treat these extra charges as normal cost for price control purposes would be no more justified than to treat as cost any discretionary increases in depreciation charges. It hardly need be emphasized that so liberal a cost-determination policy could not be reconciled with price control. 